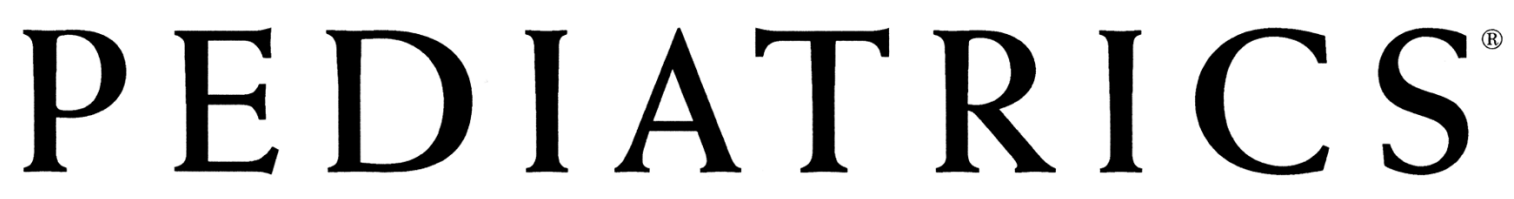

OFFICIAL JOURNAL OF THE AMERICAN ACADEMY OF PEDIATRICS

\title{
Prevalence of Overweight in Dutch Children With Down Syndrome
}

Helma B.M. van Gameren-Oosterom, Paula van Dommelen, Yvonne Schönbeck, Anne Marie Oudesluys-Murphy, Jacobus P. van Wouwe and Simone E. Buitendijk

Pediatrics 2012;130;e1520; originally published online November 12, 2012;

DOI: $10.1542 /$ peds.2012-0886

The online version of this article, along with updated information and services, is located on the World Wide Web at:

http://pediatrics.aappublications.org/content/130/6/e1520.full.html

PEDIATRICS is the official journal of the American Academy of Pediatrics. A monthly publication, it has been published continuously since 1948. PEDIATRICS is owned, published, and trademarked by the American Academy of Pediatrics, 141 Northwest Point Boulevard, Elk Grove Village, Illinois, 60007. Copyright (C) 2012 by the American Academy of Pediatrics. All rights reserved. Print ISSN: 0031-4005. Online ISSN: 1098-4275.

\section{American Academy of Pediatrics}

DEDICATED TO THE HEALTH OF ALL CHILDREN ${ }^{m}$ 


\section{Prevalence of Overweight in Dutch Children With Down Syndrome}

WHAT'S KNOWN ON THIS SUBJECT: Some groups of children are especially prone to develop overweight and obesity. Overweight in children affects their physical and psychological health and shortens life expectancy. Overweight in children with Down syndrome (DS) is attributed to their commonly found comorbidities.

WHAT THIS STUDY ADDS: This study provides prevalence rates of overweight and obesity in a nationwide sample of otherwise healthy children with DS. Overweight is observed from young ages in healthy children with DS and those with severe congenital heart defects.

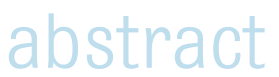

OBJECTIVE: Prevalence of overweight in children is increasing, causing various health problems. This study aims to establish growth references for weight and to assess the prevalence rates of overweight and obesity in a nationwide sample of Dutch children with Down syndrome (DS), taking into account the influence of comorbidity.

METHODS: In 2009, Iongitudinal growth data from Dutch children with trisomy 21 who were born after 1982 were retrospectively collected from medical records of 25 Dutch regional specialized DS centers. "Healthy" was defined as not having concomitant disorders or having only a mild congenital heart defect. Weight and BMI references were calculated by using the LMS method, and prevalence rates of overweight and obesity by using cutoff values for BMl as defined by the International Obesity Task Force. Differences in prevalence rates were tested by multilevel logistic regression analyses to adjust for gender and age.

RESULTS: Growth data of 1596 children with DS were analyzed. Compared with the general Dutch population, healthy children with DS were more often overweight ( $25.5 \%$ vs $13.3 \%$ in boys, and $32.0 \%$ vs $14.9 \%$ in girls) and obese (4.2\% vs $1.8 \%$, and $5.1 \%$ vs $2.2 \%$, respectively). Prevalence rates of overweight between DS children with or without concomitant disorders did not vary significantly.

CONCLUSIONS: Dutch children with DS have alarmingly high prevalence rates of overweight and obesity during childhood and adolescence. Health care professionals should be aware of the risk of overweight and obesity in children with DS to prevent complications. Pediatrics 2012;130:e1520-e1526
AUTHORS: Helma B.M. van Gameren-0osterom, MD, ${ }^{a}$ Paula van Dommelen, PhD, ${ }^{b}$ Yvonne Schönbeck, MSc, ${ }^{a}$ Anne Marie Oudesluys-Murphy, MB, PhD, ${ }^{c}$ Jacobus P. van Wouwe, MD, PhD, ${ }^{a}$ and Simone E. Buitendijk, MD, MPH, $\mathrm{PhD}^{\mathrm{d}}$

Departments of a Child Health and ${ }^{b}$ Life Style, Netherlands Organization for Applied Scientific Research, TNO, Leiden, Netherlands; and ${ }^{C}$ Department of Pediatrics, ${ }^{d} L e i d e n$ University Medical Centre, Leiden, Netherlands

\section{KEY WORDS}

growth, Down syndrome, congenital abnormalities/anomalies, weight status, obesity

\section{ABBREVIATIONS}

CHD—congenital heart defect

DS-Down syndrome

SDS-SD score

www.pediatrics.org/cgi/doi/10.1542/peds.2012-0886

doi:10.1542/peds.2012-0886

Accepted for publication Aug 3, 2012

Address correspondence to Helma B.M. van Gameren-0osterom, MD, TN0, Post Office Box 2215, 2301 CE Leiden, Netherlands. E-mail: helma.vangameren@tno.nl

PEDIATRICS (ISSN Numbers: Print, 0031-4005; Online, 1098-4275) Copyright (C) 2012 by the American Academy of Pediatrics FINANCIAL DISCLOSURE: The authors have indicated they have no financial relationships relevant to this article to disclose.

FUNDING: Financially supported by grant 150020031 of the Netherlands Organization for Health Research and Development (ZonMw) and by the Tamarinde foundation (Stichting Tamarinde). 
The worldwide increase in the prevalence of overweight and obesity in children is alarming. ${ }^{1}$ Overweight and obesity are even more common in children with Down syndrome (DS). One-third to one-half of children with DS are overweight. These rates vary because of differences in study population, methods, and cutoff values used in the studies. ${ }^{2-6}$

Overweight and obesity cause both psychological and physical health problems in children, such as low selfesteem, depressive symptoms, lower general physical condition, and metabolic complications. It is not known whether all these consequences of overweight and obesity in children in the general population are to be expected in children with DS because no data have yet been published on the effect of overweight and obesity in children with DS. Another consequence of overweight and obesity in children is the increased risk of becoming obese adults, which means having an increased risk for cardiovascular diseases, musculoskeletal disorders, and metabolic disorders at an older age. Because of the shorter life expectancy, it is doubtful whether these full complications will occur among people with DS. One study of adults with DS showed that obesity appears to play an important role in the pathophysiology of obstructive sleep apnea; the apnea hypopnea index was highly correlated with the degree of obesity. ${ }^{7,8}$ However, it is plausible that complications such as poor general physical condition and musculoskeletal disorders will occur in children with DS.

Up to now, many explanations for the higher prevalence of overweight and obesity in DS were based on the presence of concomitant disorders. Hypothyroidism, for example, is more common in children with DS and predisposes to increased body weight.9,10 Therefore, it is important to know the prevalence of overweight and obesity in children with DS not only generally but also specifically for those children with and without comorbidity. Children with DS have a high risk of concomitant disorders that are known to influence body weight both positively and negatively. ${ }^{11-13}$ This study aims to establish specific growth references for weight in children with DS and to assess the prevalence rates of overweight and obesity in a nationwide sample of Dutch children with DS, while taking into account the influence of comorbidity.

\section{METHODS}

Data were collected from medical records of children attending one of the hospital-based regional outpatient clinics for children with DS in the Netherlands. All these clinics were approached for participation to collect representative nationwide data. Between July 2009 and February 2010, the first author visited the participating clinics and collected retrospective anonymous data on growth from 2000 onward, medical conditions, and background information. Additionally, some child health physicians involved in the care of adolescents with DS supplied data by completing standard forms. Because all children visit one of these clinics providing standard medical care for children with DS by using a welldefined screening program, their health status is accurate. ${ }^{14}$

Dutch children with trisomy 21 karyotype and born after 1982 were selected. Growth data included measurements of weight, height, and head circumference. In this study, only weight and BMI are discussed. Full details of data collection were presented in our previous article on healthy growth in children with DS.15 The children were categorized into 4 health categories (Table 1): (1) "healthy": no concomitant disorders and negative screening results
TABLE 1 Characteristics of the Various Health Categories in the Study Population

or only mild congenital heart defect (CHD; hemodynamically stable); (2) severe $\mathrm{CHD}$ (hemodynamically unstable and needing surgical intervention or medication or having pulmonary vascular disease); (3) hypothyroidism; and (4) other disorders and treatments known to influence growth and children with multiple concomitant disorders. Because our previous study demonstrated that children without concomitant disorders or with only mild CHD have the same growth pattern, ${ }^{15}$ these children are pooled to form the healthy category. The new growth references established in this study as well as the prevalence rates were based on measurements of this otherwise healthy group of children.

All measurements of children with $\geq 1$ outlying measurements were excluded. 
Outliers were defined as SD scores (SDS) $>4$ or $<-6$ for weight, $>5$ or $<-7$ for birth weight, and $>2$ or $<-6$ for height, by using the age and gender-specific references of the general Dutch population (Fourth Dutch Growth Study, 1997). ${ }^{16}$ BMl was calculated as weight/height ${ }^{2}$ and expressed as $\mathrm{kg} / \mathrm{m}^{2}$.

Specific reference charts for weightfor-age were established for children with DS up to the age of 15 months. Reference charts reflect the range of normal growth of a healthy child. However, the present distribution of weight in the population at older ages is not something to be aimed for because of the current increase in the proportion of children with obesity. ${ }^{17-19}$ Therefore, references for weight-forage are plotted in this study only for the younger ages where there still is a normal distribution of weight. References were constructed by using the LMS method, which summarizes the distribution by 3 age-dependent smooth curves representing the skewness ( $L$ curve), median ( $M$ curve), and coefficient of variation (S curve) ${ }^{20}$ The references were fitted in $\mathrm{R}$ Version 2.9.0 by using Generalized Additive Models for Location Scale and Shape. ${ }^{21}$ A log transformation of age was applied to expand the ages where growth velocity is high and compress ages where growth velocity is low. Worm plots were used as a diagnostic tool for visualizing how adequate our models fitted the data. ${ }^{22}$

Prevalence rates of overweight and obesity were calculated separately for boys and girls with DS within the various health categories. To obtain accurate prevalence rates, cutoff values for $\mathrm{BMI}$ as defined by the International Obesity Task Force were used on the LMS parameters of BMI distribution in the DS study sample. ${ }^{23}$ All overweight rates in this study include obesity. The prevalence rates were compared between children with DS within the various health categories and were compared with the prevalence rates of overweight and obesity of children in the general Dutch population (Fifth Dutch Growth Study, 2009). ${ }^{17}$ Multilevel logistic regression analyses, adjusted for gender and age, were performed to test the differences in prevalence rates of children with DS within the various health categories.

\section{RESULTS}

Growth data of 1596 Dutch children with trisomy 21 were collected from medical records of 25 specialized DS clinics (83\% of all DS clinics in the Netherlands) and from the participating youth health care physicians. This sample included 891 boys $(55.8 \%)$ and 705 girls, with 6614 and 5322 measurements for weight, respectively. Table 2 shows the number of subjects and weight measurements, specified by the various health categories. The major group is formed by the otherwise healthy children (41.6\%). The children with severe CHD represent $16.9 \%$, the children with hypothyroidism represent $7.5 \%$, and the category with various other disorders represents $34.1 \%$.

Growth references for weight-for-age were plotted for ages 0 to 15 months based on 199 boys and 156 girls, yielding 959 measurements for boys and 761 for girls. Table 3 summarizes the LMS values, arranged by age and gender. Mean birth weight was $3.1 \mathrm{~kg}$ for boys and $3.0 \mathrm{~kg}$ for girls with DS. Compared with the general Dutch population (1997), mean birth weight of children with DS was 1.1 SD lower in boys and 0.9 SD lower in girls. At the age of 15 months, mean weight was $9.7 \mathrm{~kg}$ for boys and $9.0 \mathrm{~kg}$ for girls, respectively, and $1.1 \mathrm{SD}$ and $1.2 \mathrm{SD}$ lower than in the general population.

Prevalence rates of overweight and obesity in otherwise healthy children with DS are presented in Table 4. The prevalence rates of overweight are also shown in Fig 1. For comparison, the prevalence rates in children from the general population are also shown in this table and figure. In total, $25.5 \%$ of the boys with DS and $32.0 \%$ of the girls were overweight. Obesity was observed in $4.2 \%$ of the boys and $5.1 \%$ of the girls with DS. The prevalence rates were roughly constant over the age ranges; from the age of 4 years on, one-quarter of the children were overweight. Compared with the general Dutch population, prevalence rates in children with DS were on average twice as high for both overweight and obesity. The rapid increase in prevalence of overweight between age 2 and 6 years is striking. This increase is clearer in children with DS than in children from the general population.

Prevalence rates of overweight of children with DS vary between children within the various health categories.

TABLE 2 Number of Children and Measurements for Weight of 1596 Dutch Children With DS, Specified by Health Categories

\begin{tabular}{|c|c|c|c|c|c|}
\hline \multirow[t]{2}{*}{ Health Category } & \multicolumn{3}{|c|}{ Number of Subjects } & \multicolumn{2}{|c|}{$\begin{array}{c}\text { Number of } \\
\text { Measurements }\end{array}$} \\
\hline & $n$ & Boys & Girls & Boys & Girls \\
\hline Healthy or only mild CHD & 664 & 387 & 277 & 2404 & 1776 \\
\hline Severe CHD & 269 & 114 & 155 & 864 & 1169 \\
\hline Hypothyroidisma & 119 & 60 & 59 & 402 & 541 \\
\hline Other disorders & 544 & 330 & 214 & 2944 & 1836 \\
\hline Total & 1596 & 891 & 705 & 6614 & 5322 \\
\hline
\end{tabular}

a Including mild CHD. 
TABLE 3 New Weight (kǵ)-for-Age References for 0 to 15 Months in Dutch Children With DS: Values of L (Skewness), M (Mean), and S (Coefficient of Variation), ${ }^{a}$ Arranged by Age and Gender

\begin{tabular}{|c|c|c|c|c|c|c|}
\hline \multirow[t]{2}{*}{ Age (wk) } & \multicolumn{3}{|c|}{ Boys } & \multicolumn{3}{|c|}{ Girls } \\
\hline & L & M & $S^{a}$ & L & M & $S^{a}$ \\
\hline 0 & 1.06 & 3.05 & 0.1930 & 0.91 & 3.03 & 0.1471 \\
\hline 2 & 1.05 & 3.36 & 0.1848 & 0.86 & 3.27 & 0.1443 \\
\hline 4 & 1.03 & 3.66 & 0.1773 & 0.82 & 3.51 & 0.1418 \\
\hline 6 & 1.02 & 3.97 & 0.1706 & 0.79 & 3.79 & 0.1395 \\
\hline 8 & 1.00 & 4.29 & 0.1645 & 0.75 & 4.07 & 0.1375 \\
\hline 10 & 0.99 & 4.62 & 0.1590 & 0.73 & 4.36 & 0.1357 \\
\hline 12 & 0.97 & 4.95 & 0.1541 & 0.70 & 4.64 & 0.1342 \\
\hline 16 & 0.94 & 5.58 & 0.1460 & 0.67 & 5.17 & 0.1316 \\
\hline 20 & 0.91 & 6.15 & 0.1395 & 0.64 & 5.67 & 0.1295 \\
\hline 24 & 0.89 & 6.65 & 0.1345 & 0.62 & 6.13 & 0.1277 \\
\hline 28 & 0.87 & 7.08 & 0.1304 & 0.62 & 6.55 & 0.1262 \\
\hline 32 & 0.84 & 7.47 & 0.1270 & 0.63 & 6.92 & 0.1246 \\
\hline 36 & 0.81 & 7.82 & 0.1240 & 0.63 & 7.25 & 0.1231 \\
\hline 40 & 0.77 & 8.13 & 0.1213 & 0.65 & 7.55 & 0.1216 \\
\hline 44 & 0.72 & 8.42 & 0.1188 & 0.67 & 7.83 & 0.1201 \\
\hline 48 & 0.66 & 8.70 & 0.1165 & 0.69 & 8.09 & 0.1186 \\
\hline 52 & 0.60 & 8.95 & 0.1143 & 0.70 & 8.34 & 0.1172 \\
\hline 56 & 0.53 & 9.19 & 0.1122 & 0.72 & 8.55 & 0.1158 \\
\hline 60 & 0.50 & 9.41 & 0.1103 & 0.74 & 8.76 & 0.1144 \\
\hline $65^{\mathrm{b}}$ & 0.39 & 9.67 & 0.1080 & 0.76 & 9.00 & 0.1127 \\
\hline
\end{tabular}

a Individual weight SDS can be calculated by SDS $=\left((\mathrm{wt}(\mathrm{kg}) / \mathrm{M})^{\mathrm{L}}-1\right) / \mathrm{L} * \mathrm{~S}$.

b Corresponding with $15 \mathrm{mo}$.
Although children with DS and severe CHD showed almost the same prevalence rates of overweight (28.1\%), the children in the category with hypothyroidism showed higher rates (35.1\%). However, after correcting for gender and age, these differences were not significant.
TABLE 4 Prevalence Rates (\%) of Overweight and Obesity in Otherwise Healthy Children With DS

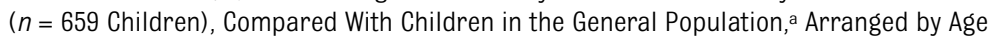
and Gender

\begin{tabular}{|c|c|c|c|c|c|c|c|c|}
\hline \multirow[t]{3}{*}{ Age, y } & \multicolumn{4}{|c|}{ Overweight } & \multicolumn{4}{|c|}{ Obesity } \\
\hline & \multicolumn{2}{|c|}{ Boys } & \multicolumn{2}{|c|}{ Girls } & \multicolumn{2}{|c|}{ Boys } & \multicolumn{2}{|c|}{ Girls } \\
\hline & DS & Popa & DS & Pop & DS & Pop & DS & Pop \\
\hline 2 & 12.0 & 8.0 & 10.8 & 8.3 & 2.0 & 0.7 & 1.0 & 0.7 \\
\hline 3 & 15.9 & 7.8 & 22.0 & 12.8 & 2.7 & 0.8 & 2.9 & 1.6 \\
\hline 4 & 22.6 & 9.1 & 31.7 & 16.3 & 4.5 & 1.1 & 5.3 & 2.6 \\
\hline 5 & 28.7 & 12.8 & 36.9 & 18.1 & 6.5 & 2.0 & 6.9 & 3.3 \\
\hline 6 & 29.9 & 13.7 & 37.4 & 18.5 & 6.5 & 2.1 & 6.8 & 3.4 \\
\hline 7 & 27.2 & 14.3 & 34.4 & 18.8 & 5.3 & 2.1 & 5.2 & 3.4 \\
\hline 8 & 24.6 & 14.7 & 30.5 & 18.0 & 4.5 & 2.2 & 3.9 & 3.2 \\
\hline 9 & 24.4 & 13.7 & 28.7 & 17.0 & 4.1 & 2.0 & 3.3 & 2.8 \\
\hline 10 & 24.3 & 12.5 & 29.1 & 16.2 & 3.8 & 1.7 & 3.3 & 2.5 \\
\hline 11 & 25.4 & 11.9 & 29.6 & 15.0 & 3.7 & 1.6 & 3.5 & 2.1 \\
\hline 12 & 26.6 & 11.9 & 30.4 & 13.6 & 3.7 & 1.6 & 4.0 & 1.8 \\
\hline 13 & 27.5 & 12.0 & 32.6 & 12.5 & 3.7 & 1.6 & 5.0 & 1.6 \\
\hline 14 & 27.2 & 12.4 & 36.3 & 12.2 & 3.6 & 1.7 & 6.6 & 1.5 \\
\hline 15 & 27.8 & 12.9 & 36.9 & 12.3 & 3.7 & 1.8 & 6.7 & 1.5 \\
\hline 16 & 29.3 & 13.4 & 38.4 & 12.8 & 4.2 & 1.9 & 7.2 & 1.6 \\
\hline 17 & 30.2 & 13.8 & 39.3 & 13.3 & 4.4 & 2.0 & 7.4 & 1.7 \\
\hline 18 & 30.7 & 13.7 & 39.8 & 13.6 & 4.5 & 1.9 & 7.5 & 1.7 \\
\hline $2-18^{b}$ & 25.5 & 12.3 & 32.0 & 14.7 & 4.2 & 1.7 & 5.1 & 2.2 \\
\hline
\end{tabular}

a Pop, General population: prevalence rates from the Fifth Dutch Growth Study, 2009.17

${ }^{b}$ Mean prevalence rate for children aged 2 to $18 \mathrm{y}$.

\section{DISCUSSION}

This study presents prevalence rates of overweight and obesity in a nationwide population-based sample of almost 1600 Dutch children with DS. A strict selection on the basis of health status of the children resulted in data based on a group of otherwise healthy children with DS. The approach of dividing the children into various health categories based on comorbidity that can influence their growth (height and/or weight) is an important part of this study and provides information on the presence of overweight and obesity in children within these various health categories. It is not only healthy children with DS who have a high prevalence of overweight and obesity, but also the children with any type of comorbidity. Prevalence rates of overweight and obesity vary between children with DS in the different health categories, but no statistically significant differences were observed.

From the age of $4,>25 \%$ of the healthy children with DS are overweight. The rapid increase in prevalence of overweight in children with DS between 2 and 6 years of age is striking, in boys as well as in girls (presented in Fig 1). In view of the fact that overweight children have an increased risk of becoming obese adults, such high prevalences are alarming, because this may lead to poor general physical condition and comorbidities such as obstructive sleep apnea, musculoskeletal disorders, and cardiovascular diseases. 7,8,24,25 This emphasizes the importance of awareness of the occurrence of overweight in children with DS at young ages.

New reference charts are established for weight-for-age for boys and girls with DS up to age 15 months and will aid in appropriate monitoring. After age 15 months, no reference charts specific for DS are established because the present distribution of weight in the population at older ages is not 


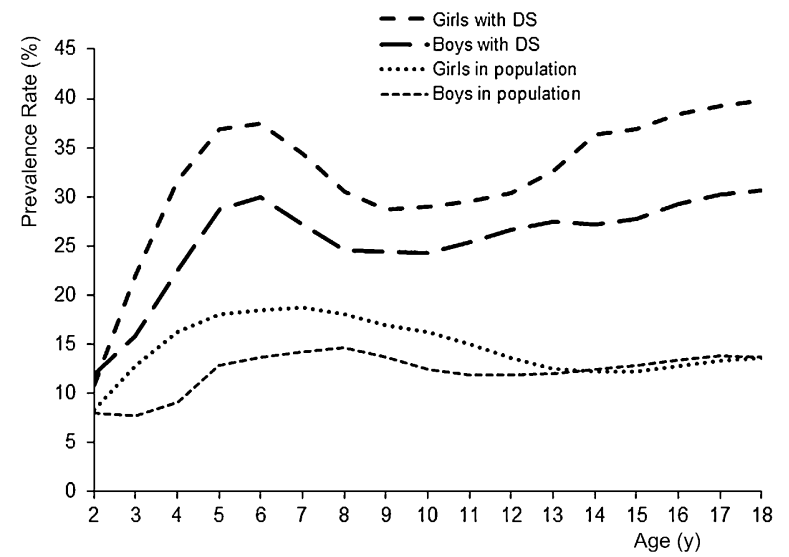

FIGURE 1

Prevalence rates (\%) of overweight in otherwise healthy children with DS ( $n=659$ children), compared with children in the general population, arranged by gender and age. Prevalence rates for general population are from the Fifth Dutch Growth Study, 2009. ${ }^{17}$

something to be aimed for. In the Netherlands, normative growth charts for weight for height and BMI for age are used for both children in general and children with DS. The normative reference charts for BMl for age include international cutoff values for overweight and obesity and for thinness grades 1 and 2.17,23,26,27 All growth charts are available at www.tno.nl/ growth. Additional research is needed to determine how sensitive and specific these international cutoff values are in children with DS. Until more information is available to improve monitoring, the currently available general weight and BMl charts will be used for growth monitoring in children with DS aged $>15$ months and seems to work well with the specific weight-toage charts for ages 0 to 15 months.

Another important result is that children with DS with severe CHD show nearly the same high prevalence rates. During the early years of life of these children, attention is mainly concentrated on their medical heart defect condition. However, our data show that it is also necessary to be aware of the need to prevent excessive weight gain. Our data indicate a higher prevalence of overweight and obesity in children with DS and hypothyroidism. This is somewhat surprising because all children with DS were screened for hypothyroidism, as advised in the guideline of the Pediatric Association of the Netherlands. ${ }^{14}$ This means that hypothyroidism is diagnosed and treated at an early stage before complaints arise and weight gain is caused.

For optimal prevention and intervention, more should be learned about the underlying cause of excessive weight gain in children with DS. One of the theories about the cause is resistance to leptin. This is a hormone excreted by adipocytes that suppresses appetite and regulates body weight. Leptin is positively correlated with body fat, so people with obesity have a type of leptin resistance. ${ }^{28,29}$ Magge et al have observed that leptin levels and the proportion of body fat were more positively correlated in children with DS than in their brothers and sisters. ${ }^{30}$ The cause of this phenomenon is unknown. Other studies investigated the presence of reduced resting metabolic rate. Small studies showed some support for this theory. ${ }^{31}$ However, Fernhall et al demonstrated no difference in metabolic rate between individuals with DS and control individuals of similar ages. ${ }^{32}$ Another theory is based on the influence of lifestyle. Higher rates of overweight and obesity might be attributed to lesser physical activity or higher nutrient intake.,33-35 Nevertheless, the few available studies on these subjects do not as yet provide convincing evidence for any specific theory.

With the knowledge we have from studies among children in the general population, we assume that physical activity and feeding patterns are likely the essential factors influencing body weight in children with DS. Additional research is needed to establish the merit of this assumption and to explore other underlying factors. As long as the underlying causes are still unknown, a specific approach to tackle the cause is not possible. However, dietary factors and insufficient physical activity are considered to be main contributors to the development of overweight. Assuming that this also applies to children with DS, we expect that they will benefit from it. Children with DS often want to keep to a strict routine to optimize their autonomy. When a healthy diet and enough physical activity is a structural part of this personal daily routine, the children will probably adhere to such a routine. Therefore, appropriate information for parents and children is essential and must be provided by youth health care workers and pediatricians. Parents need to know what a healthy weight is for their child with DS. With this in mind, they can support their child to achieve and maintain a healthy weight. These approaches to prevent excessive weight gain are an important task for professionals involved in the care for children with DS.

\section{CONCLUSIONS}

We observed an alarming prevalence of overweight and obesity in Dutch children with DS. Overweight and obesity are observed from a young age in otherwise healthy children with DS as well as in children with DS and severe CHD. Health care professionals should be aware of the risk of overweight and 
obesity in children with DS and should ensure that growth is monitored regularly in all children with DS, thus enabling early detection of inappropriate weight gain and starting appropriate interventions where necessary. In this way, undesirable psychological and physical health consequences may be prevented. Parents and children also need appropriate information to prevent

\section{REFERENCES}

1. World Health Organization. World Health Assembly Resolution WHA57.17 on a Global Strategy on Diet, Physical Activity and Health. Geneva, Switzerland: World Health Organization, 2004

2. Styles ME, Cole TJ, Dennis J, Preece MA. New cross sectional stature, weight, and head circumference references for Down's syndrome in the UK and Republic of Ireland. Arch Dis Child. 2002;87(2): 104-108

3. Myrelid A, Gustafsson J, Ollars B, Anneren G. Growth charts for Down's syndrome from birth to 18 years of age. Arch Dis Child. 2002;87 (2):97-103

4. Chumlea WC, Cronk CE. Overweight among children with trisomy. J Ment Defic Res. 1981;25 (pt 4):275-280

5. Rimmer JH, Yamaki K, Lowry BM, Wang E, Vogel LC. Obesity and obesity-related secondary conditions in adolescents with intellectual/ developmental disabilities. J Intellect Disabil Res. 2010;54(9):787-794

6. Grammatikopoulou MG, Manai A, Tsigga M, Tsiligiroglou-Fachantidou A, Galli-Tsinopoulou A, Zakas A. Nutrient intake and anthropometry in children and adolescents with Down syndrome-a preliminary study. Dev Neurorehabil. 2008;11(4):260-267

7. de Miguel-Diez J, Villa-Asensi JR, AlvarezSala JL. Prevalence of sleep-disordered breathing in children with Down syndrome: polygraphic findings in 108 children. Sleep. 2003;26(8):1006-1009

8. Trois MS, Capone GT, Lutz JA, et al. Obstructive sleep apnea in adults with Down syndrome. J Clin Sleep Med. 2009;5(4):317-323

9. Hunter I, Greene SA, MacDonald TM, Morris $A D$. Prevalence and aetiology of hypothyroidism in the young. Arch Dis Child. 2000; 83(3):207-210

10. Van Trotsenburg AS. Early Development and the Thyroid Hormone State in Down Syndrome. excessive weight gain. We expect that a structured, healthy lifestyle, including eating a healthy diet and having sufficient physical activity, will be especially effective in children with DS because of their tendency to follow a strict routine. Specific prevention programs to prevent excessive weight gain that are suitable for children with DS and support their families may be valuable.

Amsterdam, Netherlands: University of Amsterdam; 2006

11. Weijerman ME, de Winter JP. Clinical practice. The care of children with Down syndrome. Eur J Pediatr. 2010;169(12): 1445-1452

12. Roizen NJ, Patterson D. Down's syndrome. Lancet. 2003;361(9365):1281-1289

13. Borstlap R, van Gameren-0osterom HBM, Lincke C, Weijerman ME, van Wieringen $\mathrm{H}$, Van Wouwe JP. An Update of the Multidisciplinar Guideline for Medical Care of Children With Down Syndrome [in Dutch]. Utrecht, Netherlands: Nederlandse Vereniging van Kindergeneeskunde; 2011

14. Van Wouwe JP, Siderius EJ, Borstlap R, Nijenhuis TA, Hirasing RA. Optimal medical care for children with Down syndrome and their parents [in Dutch]. Ned Tijdschr Geneeskd. 2001;145(34):1617-1621

15. Van Gameren-0osterom HBM, Van Dommelen P, Oudesluys-Murphy AM, Buitendijk SE, Van Buuren S, Van Wouwe JP. Healthy growth in children with Down syndrome. PLOS ONE. 2012;7(2):e31079

16. Fredriks AM, van Buuren S., Burgmeijer RJ, et al. Continuing positive secular growth change in the Netherlands 1955-1997. Pediatr Res. 2000;47(3):316-323

17. Schönbeck $Y$, Talma $H$, van Dommelen $P$, et al. Increase in prevalence of overweight in Dutch children and adolescents: a comparison of nationwide growth studies in 1980, 1997 and 2009. PLOS ONE. 2011;6(11): e27608

18. Cole TJ, Roede MJ. Centiles of body mass index for Dutch children aged 0-20 years in 1980 - a baseline to assess recent trends in obesity. Ann Hum Biol. 1999;26(4):303-308

19. Fredriks $A M$, van BS, Sing RA, Wit JM, Verloove-Vanhorick SP. Alarming prevalences of overweight and obesity for children of

\section{ACKNOWLEDGMENTS}

We thank all pediatricians, physicians for the intellectually disabled, and youth health care physicians who provided data for their efforts in enabling this study. We thank the executive committee of the Down Syndrome Medical Interest Group of the Pediatric Association of the Netherlands for approaching the physicians.
Turkish, Moroccan and Dutch origin in the Netherlands according to international standards. Acta Paediatr. 2005;94(4):496-498

20. Cole TJ, Green PJ. Smoothing reference centile curves: the LMS method and penalized likelihood. Stat Med. 1992;11(10): 1305-1319

21. Rigby RA, Stasinopoulos DM. Generalized additive models for location, scale and shape. Appl Stat. 2005;54(3):507-554

22. Van Buuren $S$, Fredriks $M$. Worm plot a simple diagnostic device for modelling growth reference curves. Stat Med. 2001;20 (8):1259-1277

23. Cole TJ, Bellizzi MC, Flegal KM, Dietz WH. Establishing a standard definition for child overweight and obesity worldwide: international survey. BMJ. 2000;320(7244): $1240-1243$

24. Freedman DS, Khan LK, Serdula MK, Dietz WH, Srinivasan SR, Berenson GS. The relation of childhood BMl to adult adiposity: the Bogalusa Heart Study. Pediatrics. 2005 115(1):22-27

25. De Kroon ML, Renders CM, Van Wouwe JP, Van Buuren S, Hirasing RA. The Terneuzen birth cohort: BMI changes between 2 and 6 years correlate strongest with adult overweight. PLOS ONE. 2010;5(2):e9155

26. Talma H, Schönbeck Y, Bakker B, Hirasing RA, van Buuren S. Growth Charts 2010: Manual to Measure and Weigh Children and Recording of Growth Charts [in Dutch]. Leiden, Netherlands: TNO, Quality of Life; 2010

27. Cole TJ, Flegal KM, Nicholls D, Jackson AA. Body mass index cut offs to define thinness in children and adolescents: international survey. BMJ. 2007;335(7612):194

28. Fleisch AF, Agarwal N, Roberts MD, et al Influence of serum leptin on weight and body fat growth in children at high risk for adult obesity. I Clin Endocrinol Metab. 2007;92(3):948-954 
29. Considine RV, Sinha MK, Heiman ML, et al. Serum immunoreactive-leptin concentrations in normal-weight and obese humans. N Engl J Med. 1996;334(5):292-295

30. Magge SN, O'Neill KL, Shults J, Stallings VA, Stettler N. Leptin levels among prepubertal children with Down syndrome compared with their siblings. J Pediatr. 2008;152(3):321-326

31. Luke A, Roizen NJ, Sutton M, Schoeller DA Energy expenditure in children with Down syndrome: correcting metabolic rate for movement. J Pediatr. 1994;125(5 pt 1):829838

32. Fernhall B, Figueroa A, Collier S, Goulopoulou S, Giannopoulou I, Baynard T. Resting metabolic rate is not reduced in obese adults with Down syndrome. Ment Retard. 2005;43(6):391-400

33. Luke A, Sutton M, Schoeller DA, Roizen NJ. Nutrient intake and obesity in prepubes- cent children with Down syndrome. J Am Diet Assoc. 1996;96(12):1262-1267

34. O'Neill KL, Shults J, Stallings VA, Stettler N. Child-feeding practices in children with down syndrome and their siblings. J Pediatr. 2005;146(2):234-238

35. Whitt-Glover MC, O'Neill KL, Stettler N. Physical activity patterns in children with and without Down syndrome. Pediatr Rehabil. 2006;9(2):158-164 


\section{Prevalence of Overweight in Dutch Children With Down Syndrome}

Helma B.M. van Gameren-Oosterom, Paula van Dommelen, Yvonne Schönbeck, Anne Marie Oudesluys-Murphy, Jacobus P. van Wouwe and Simone E. Buitendijk Pediatrics 2012;130;e1520; originally published online November 12, 2012; DOI: $10.1542 /$ peds. $2012-0886$

\section{Updated Information \& Services}

\section{References}

Subspecialty Collections

Permissions \& Licensing

Reprints including high resolution figures, can be found at: http://pediatrics.aappublications.org/content/130/6/e1520.full. html

This article cites 12 articles, 3 of which can be accessed free at:

http://pediatrics.aappublications.org/content/130/6/e1520.full. html\#ref-list-1

This article, along with others on similar topics, appears in the following collection(s):

Genetics \& Dysmorphology

http://pediatrics.aappublications.org/cgi/collection/genetics_a nd_dysmorphology

Information about reproducing this article in parts (figures, tables) or in its entirety can be found online at: http://pediatrics.aappublications.org/site/misc/Permissions.xh tml

Information about ordering reprints can be found online: http://pediatrics.aappublications.org/site/misc/reprints.xhtml

PEDIATRICS is the official journal of the American Academy of Pediatrics. A monthly publication, it has been published continuously since 1948. PEDIATRICS is owned, published, and trademarked by the American Academy of Pediatrics, 141 Northwest Point Boulevard, Elk Grove Village, Illinois, 60007. Copyright (C) 2012 by the American Academy of Pediatrics. All rights reserved. Print ISSN: 0031-4005. Online ISSN: 1098-4275.

\section{American Academy of Pediatrics}

DEDICATED TO THE HEALTH OF ALL CHILDREN ${ }^{m}$ 